International Journal of Food Microbiology, Volume 155, Issues 1-2, 2 April 2012, Pages 29-35

\section{Modelling of Bacterial Growth with Shifts in Temperature Using Automated Methods with Listeria monocytogenes and Pseudomonas aeruginosa as examples}

\author{
Applied Microbiology Group, \\ Cranfield Health \\ Cranfield University \\ Cranfield MK43 OAL, U.K.
}

July 2011

Page 1 
39 Abstract

40

41 Time to detection (TTD) measurements using turbidometry allow a facile method for the

42 measurement of bacterial growth rates under isothermal conditions. Growth rate measurements

43 were carried out for Listeria monocytogenes at 25,30 and $37^{\circ} \mathrm{C}$ and for Pseudomonas aeruginosa

44 over the temperature range 25 to $45^{\circ} \mathrm{C}$. No lags were observed with any of the isothermal studies.

45 The classical 3 parameter logistic model was rearranged to provide the theoretical foundation for

46 the observed TTD. A model was subsequently developed for the analysis of TTD data from non-

47 isothermal studies based on the Malthusian approximation of the logistic model. The model was

48 able to predict the TTD for cultures of $L$. monocytogenes or $P$. aeruginosa undergoing simple

49 temperature shunts (e.g. 25 to $37^{\circ} \mathrm{C}$ and vice versa), and for a multiple temperature shunt for $\mathrm{L}$.

50 monocytogenes $\left(25-37-25-37^{\circ} \mathrm{C}\right.$ and $\left.37-25-37-25^{\circ} \mathrm{C}\right)$ over a period of 24 hours. In no case did a

51 temperature shunt induce a lag.

Page 2

CONFIDENTIAL: Cranfield Health: Applied Microbiology

This document may not be reproduced or disclosed to third parties without prior authorisation. 
53 The measurement of microbial growth rates, especially its temperature dependency, is of

54 fundamental importance in food microbiology. For many food pathogens growth above 25 and below $45^{\circ} \mathrm{C}$ is usually rapid with an optimum around $37^{\circ} \mathrm{C}$. Below 5 degrees only a few (often spoilage, e.g. Pseudomonas aeruginosa, but pathogens are also represented e.g. Listeria monocytogenes) have growth rates that would give rise to concern. This has been shown, for example, by Thomas and O'Bierne (2000) on the temperature abuse of vegetables with respect to spoilage (lactic acid bacteria) and risk (L. monocytogenes).

60

Within the literature several studies have looked at the effect of non-isothermal conditions on microbial growth using established modeling methods (e.g. Baranyi et al., 1995; Bovill et al., 2000; Dalgaard et al., 2002; Giannakourou et al., 2005; Koutsoumanis, 2001; Koutsoumanis et al., 2006; Li and Torres, 1993; Taoukis et al., 1999; Zwietering et al., 1994). The aim of many of these studies was to test the ability of using models based on growth data obtained isothermally to predict growth under non-isothermal conditions. Zwietering et al., (1994) concluded that, within the exponential phase, the hypothesis of no lag occurrence was accepted statistically in more than $70 \%$ of their experiments for Lactobacillus plantarum, however within the lag phase, the hypothesis of additional lag occurrence was accepted statistically in more than $90 \%$ of their experiments.

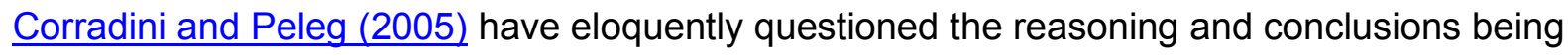
drawn from the use of the empirical standard primary and secondary models used to interpret and predict data from isothermal and fluctuating temperature studies. They suggest abandoning specific formats and using, instead, a generalized scheme for both primary and secondary modeling, "in the absence of a decisively superior theoretical model... [ad hoc empirical models] have the advantage of being simpler mathematically and free of assumptions that require independent verification".

Page 3 
79 Automated techniques such as turbidometry tend to come under fire from traditional

80 microbiologists since they cannot directly reproduce the standard microbial growth curve, which the 81 multitude of primary models are fitted to (Augustin et al. 1999; Dalgaard et al. 1994; McClure et al. 82 1993), yet their very persistence reflects their ease of use, the high quantity and quality of the data 83 obtained and the large savings in consumable costs over that of the traditional (plate-count)

84 methods. We have recently shown that the modified Gompertz and modified logistic models are at 85 odds with the observed time to detection data obtained using turbidometry (Mytilinaios et al. 2011).

86 The classic logistic model (and by default the Baranyi equation) were the only models used able to 87 reconstruct the observed TTD data. The three parameter model has a firm (if simple) theoretical 88 foundation. Its application to standard microbiological data results in mismatch due to 89 methodological inadequacies (plate counting) and the presence of lag and so is rarely used in its 90 original form. Herein we further examine the application of the basic logistic model to microbial 91 growth data (obtained as TTD) and use small temperature shifts (or shunts) to examine their effect on the growth rates of Listeria monocytogenes and Pseudomonas aeruginosa.

Page 4 


\subsection{CULTURE PREPARATION:}

95

96

Pseudomonas aeruginosa (ATCC 15442) or Listeria monocytogenes (L-252, an industrial isolate provided by Nestlé Research Centre, Lausanne- obtained from contaminated terrine) was grown overnight in conical flasks containing $80 \mathrm{ml}$ Tryptone Soya Broth, TSB (Oxoid CM 129) shaking continuously at $30^{\circ} \mathrm{C}$. The cells were harvested, centrifuged $(510 \mathrm{~g}, 10$ minutes) and the resulting cell pellets resuspended in $2 \mathrm{ml} \mathrm{TSB}$. The inoculum was standardised by diluting to an approximate $\mathrm{OD}=0.5$ at $600 \mathrm{~nm}$ giving approximately $2 \times 10^{9} \mathrm{cfu} / \mathrm{ml}$. This standardised culture was subject to either ten decimal or ten half-fold dilutions in TSB.

\subsection{PREPARATION OF MICRO-ARRAY Plates}

Each well in the Bioscreen micro-array plates was filled as follow: all wells except column 10 received $200 \mu$ l of growth broth (TSB). The wells of column 10 were given $400 \mu$ l of the appropriate serial dilutions (decimal or half fold), with the highest inoculum (the zero dilution) in well 100. Using a multi-pipette, $200 \mu$ l were removed from each well of column 10 and transferred into the wells of column 9 , mixed by repeated syringing, and then $200 \mu \mathrm{l}$ were removed (using new tips) from the wells of column 9 and transferred to column 8 etc. This was repeated across the plate discarding $200 \mu$ lafter the final mixing in column 1.

From the -5 and -6 decimal dilutions, $0.1 \mathrm{ml}$ of each was transferred and spread onto previously prepared tryptone soya agar (TSA) plates in triplicate and incubated at $30^{\circ} \mathrm{C}$ for 2 days. Plates with $<300$ cfu were counted and the approximate log number of the initial (zero dilution) culture calculated.

\section{Page 5}


For the study of the growth rates, identical plates were placed in different Bioscreens set at particular temperatures. After a given time of incubation the plates were swapped between the machines, without changing the running of the machines. Typical experiments lasted 1 to 2 days.

120 The optical density of the wells was read at $600 \mathrm{~nm}$ every ten minutes.

122 One particular effect was noted with Bioscreen data when the plates were removed from a higher 123 incubation temperature to a lower (but not vice-versa); a kink in the OD/time plot due to the 124 temporary presence of condensation on the underneath of the lid of the Bioscreen plates. In 125 general the condensation took between 30 to 50 minutes to evaporate. Thus, TTD which met the 126 OD criterion were censored during the 30 to 50 minutes after the transfer.

\subsection{DATA ANALYSIS}

129 From the resulting Bioscreen OD/time data, the background OD due to the media was removed 130 from each. A time to detection (TTD) criterion of $\mathrm{OD}=0.2$ was then used on the background 131 corrected data: TTD were found using linear interpolation between OD/time values which 132 straddled the $\mathrm{OD}=0.2$ value

\subsection{Model DeVelopment}

134 Theoretical Background: From the classical logistic equation

$$
N=\frac{M}{1+\left(\frac{M}{N_{0}}-1\right) e^{-\mu t}}
$$

136 where $\mu$ is the specific growth rate and $M$ is the maximum population density (also known as the 137 carrying capacity, cfu/ml), the time taken $\left(T T D_{N}\right)$ to reach a specific population level $(\mathrm{N})$ from a given initial value $\left(\mathrm{N}_{0}, \mathrm{cfu} / \mathrm{ml}\right)$ is given by

Page 6 


$$
T T D_{N}=-\frac{1}{\mu} \ln N_{0}+\frac{1}{\mu} \ln \left(\frac{N\left(M-N_{0}\right)}{M-N}\right)
$$

140 The $T T D_{N}$ is defined as the time to reach a given detection threshold (e.g. an optical density of 0.2 )

141 for which $N_{d}$ is the equivalent microbial numbers per $\mathrm{ml}$. If the assumption that $M>>N_{0}$ is made 142 then this can be approximated by

$$
T T D=-\frac{1}{\mu} \ln N_{0}+\frac{1}{\mu}\left\{\frac{N_{d} M}{M-N_{d}}\right\}
$$

144 When $N_{0}=1$, the TTD is given by the right hand expression of eq.3, if $M>>N_{d}$ then this can be approximated by $\mathrm{N}_{\mathrm{d}} / \mu$. Hence, a plot of the initial inoculum against the TTD will give a gradient equal to the negative reciprocal of the growth rate, the TTD intercept at $N_{0}=1$, is the time taken for one organism to reach the TTD criterion. This expression can be considered as the basis of the methodology of Cuppers and Smelt (1993) described below. In the presence of a lag equation 2 can be supplemented with a lag term, else the Baranyi equation can be used, but the required parameters have to be found using a more involved numerical technique.

Geometric or Malthusian model

For a given set of environmental conditions a plot of the log of the initial inoculum size against the time to detection (TTD) gives a straight line relationship with gradient equal to the reciprocal of the specific growth rate (uppers and Smelt 1993). In the absence of a lag the line will intersect the log initial inoculum axis at the detection value for the given OD criterion used.

If two microtitre plates each containing identically prepared multiple inocula are incubated at different temperatures then each inoculum will grow at a rate dictated by the temperature and media conditions. The difference between the two plates will be governed only by the differential effect of the temperature. For each initial inoculum the time to detection can be given by

Page 7 
164 Where $\log I$ is the $\log$ of the initial inoculum used, $\log I_{\mathrm{D}}$ is the $\log$ of the detection number and $\mathrm{m}$ is 165 the gradient of the TTD, log / plot.

166 We hypothesise that if at time $t_{i}$ the incubation temperature is changed then, whether in the 167 absence or not of an induced lag, the growth rate will increase or decrease to meet the demands of 168 the new incubation temperature. In the absence of any induced lag Figure 1 shows the expected 169 result on the time to detection/log initial inoculum plot. Incubation at temperature $T_{0}$ gives an 170 observed gradient of $M_{0}$; at time $t_{i}$, the temperature is changed to $T_{1}$ (where, in this case, $T_{0}$ is 171 more optimal for growth than $T_{1}$ ), the gradient changes to $M_{1}$, commensurate with the new 172 incubation temperature.

174 From simple geometrical arguments it can be shown that the TTD for multiple changes of 175 temperature is given by equation 5 .

177 For time: $t_{i}<t<t_{i+1}$, for $i=0,1,2, \ldots$, where $t_{0}=0$,

180 For example,

For $\mathrm{i}=0$ 
187 If lags are induced at $t_{i}$, then the expression for $t_{i}$ can be replaced by $t_{i}=t_{i}+\lambda_{i}$. For a given

188 experiment the values of $t_{i}$ are fixed.

189 Since the models are simple linear models, the majority of the modelling was carried out using 190 Excel (Microsoft) and the data analysis add-in package.

Page 9 


\section{Results}

192

193

194

\subsection{ISO-THERMAL STUDIES}

A plot of the optical density/time curves for multiple inocula of Listeria monocytogenes 252 (from $1.2 \times 10^{9} \mathrm{cfu} \mathrm{ml}^{-1}$ to $1 \times 10^{4} \mathrm{cfu} \mathrm{ml}^{-1}$ ) incubated at $25^{\circ} \mathrm{C}$ is shown in Figure 2 (without background correction carried out). From analyses of the curves for inocula which had initial OD greater than the background it was evident that there was no lag present. A plot of the time to detection defined as the time to reach an $\mathrm{OD}=0.2$ against the log of the initial inoculum gave a straight line plot (Figure 3a). The gradient of the fitted line is the reciprocal of the growth rate, and the intercept on the TTD axis is the time taken for one organism to reach the detection criterion. For zero lag the line cuts the log initial inoculum axis at the log inoculum size equivalent to the optical density of the TTD criterion. The microbial density obtained from direct plating of an OD $=0.2$ at $600 \mathrm{~nm}$ in the Bioscreen was equivalent to $9.09 \log _{10} \mathrm{cfu} \mathrm{ml}^{-1}(95 \% \mathrm{Cl}: 8.97-9.21)$. Similar findings with respect to lag and the fit of the TTD data were found with data obtained at 30 and $37^{\circ} \mathrm{C}$ (Table 1).

\section{Pseudomonas aeruginosa was analysed in a similar manner but over a wider range of} temperatures (Table 1). An optimum growth temperature of approximately $39^{\circ} \mathrm{C}$ was apparent; with a specific growth rate of $1.51 \mathrm{ln} \mathrm{cfu} / \mathrm{ml} / \mathrm{hr}$. None of the studies conducted showed the presence of a lag. Figure $3 \mathrm{~b}$ shows data obtained at 37 and $30^{\circ} \mathrm{C}$, the fitted lines cut the log inoculum axis at the detection number threshold value. The data shown for growth at $37^{\circ} \mathrm{C}$ has approximately constant variance until the initial inoculum level is less than $10^{2} \mathrm{cfu} / \mathrm{ml}$. Below this level the variance increases. To preclude the need for weighted regression data below this threshold were censored in the regression fits.

\subsection{NON-ISOTHERMAL StUdiES}

Two temperature shunt studies

Page 10 
Listeria monocytogenes: Figure 4 shows the observed TTD data from two plates incubated initially for 400 mins at 25 and $37^{\circ} \mathrm{C}$ and then transferred to the Bioscreens incubating at 37 and $25^{\circ} \mathrm{C}$ respectively; Figure 5 shows a similar experiment done with incubation at 30 and $37^{\circ} \mathrm{C}$. The gradients of the lines are given in Table 2 and in each case the gradients obtained follow approximately those found from the isothermal data (Table1). Further, there were no indications of induced lags after the plates were exchanged. A lag would result in a vertical gap between the two rates.

Pseudomonas aeruginosa: Table 4 gives the observed gradients and intercepts for a temperature shunt of 25 to $39^{\circ} \mathrm{C}$ and vice versa and also for 34 and $39^{\circ} \mathrm{C}$. Figure 6 shows the data obtained from the Bioscreen incubating at $37^{\circ} \mathrm{C}$ for the 37 to $30^{\circ} \mathrm{C}$ shunt. The initial incubation at $37^{\circ} \mathrm{C}$ gave a gradient of $-95.2(-99.90$ to $-90.50: 95 \% \mathrm{Cl}) \mathrm{mins} / \log _{10} \mathrm{cfu} / \mathrm{ml}$; the gradient of the plate initially incubated at $30^{\circ} \mathrm{C}$ but placed into the $37^{\circ} \mathrm{C}$ incubator after 300 mins was -92.96 (-96.9 to -89.02 : $95 \% \mathrm{Cl}) \mathrm{mins} / \log _{10} \mathrm{cfu} / \mathrm{ml}$. The horizontal separation of the two was calculated as 0.887 $\log _{10} \mathrm{cfu} / \mathrm{ml}$., i.e. the plate incubated at $30^{\circ} \mathrm{C}$ was growth retarded relative to growth at $37^{\circ} \mathrm{C}$ by just less than 1 log cfu/ml after 300 minutes of incubation.

Multiple Temperature Shunts: Figure 7 shows the observed times to detection for multiple initial inocula of L.monocytogenes undergoing either a $37-25-37-25^{\circ} \mathrm{C}$ or a $25-37-25-37^{\circ} \mathrm{C}$ temperature incubation sequence, changing temperatures after 360, 500 and 900 minutes. The observed gradients were $-107.9,-179.3,-105.2,-N A$ for the $37-25-37-25^{\circ} \mathrm{C}$ sequence and $-193.5,-104.7,-$ $172.6,-110.0$ for the $25-37-25-37^{\circ} \mathrm{C}$ sequences respectively. Superimposed on Figure 7 are the predicted values from the Geometric model, the TTD predictions of which are based on the growth rate data given in Table 1.

Modelling

The Geometric model (Eq. 5)can be either used to predict the outcome of hypothetical experiments -as was done for the multiple temperature shunt with Listeria shown in Figure 7, or can be used to

\section{Page 11}


243 fit the observed data by minimising the sum of squares of the errors. Another method of using the

244 predictive capacity of the model is to predict the TTD observed from a single Bioscreen incubating 245 at a given temperature, when identical plates are moved in or out of the machine. Figure 8 shows a 246 prediction of the pattern of TTD/log initial inocula from the single Bioscreen incubating at $37^{\circ} \mathrm{C}$.

247 Using the growth rates described in Table 1, in 360 minutes the model predicts that 3.27 logs of 248 growth will occur in this plate, whereas the other plate incubating in the other machine at $25^{\circ} \mathrm{C}$ will 249 increase by only 1.97 logs. When the latter plate is placed in the machine at $37^{\circ} \mathrm{C}$, if there are no 250 lags then over the next 240 minutes there will be further increase of 2.18 logs in this plate. By 251 calculating the log increase in the numbers of $L$. monocytogenes at $37^{\circ} \mathrm{C}$ and that incubated at $25225^{\circ} \mathrm{C}$ and then subsequently placed at $37^{\circ} \mathrm{C}$, the pattern shown in Figure 8 was obtained. The 253 observed data are overlain on the predicted lines. No lags were observed. 


\section{Discussion}

256 The simple, classical 3-parameter logistic model can model the time to detection data obtained 257 from turbidometric experiments using multiple initial inocula incubated iso-thermally. In all cases 258 studied no lags were observed either from the OD/incubation time plots or from the plotted or modelled data. Plots of the log initial inoculum against the TTD cut the log $I_{0}$ axis at $9.22 \log _{10}$ $\mathrm{cfu} / \mathrm{ml}\left(95 \% \mathrm{Cl} 9.05-9.4 \log _{10} \mathrm{cfu} / \mathrm{ml}\right)$ and at $9.15 \log _{10} \mathrm{cfu} / \mathrm{ml}(95 \% \mathrm{Cl} 8.9-9.4)$ for $L$. monocytogenes and $P$. aeruginosa respectively. The detection number $\left(\mathrm{N}_{\mathrm{d}}\right)$ for each species was confirmed by plate counting and from calibration curves of OD against microbial numbers. In the presence of a lag the plot would fail to cross the axis at the $\mathrm{N}_{\mathrm{d}}$, and a vertical separation equal to the lag between the $x$-axis and the TTD of the $N_{d}$ would be present. This was not observed in any of the isothermal studies performed.

The linear approximation (eq.4) to the logistic expression (eq.2) assumes that $M>>N_{0}$ and also that $M>>N_{d}$; when $N_{0}=N_{d}, T T D=0$. If $M<10 N_{d}$ then curvature of the observed TTD occurs, if $M$ $<3 \mathrm{~N}_{\mathrm{d}}$ then this curvature is substantial and the mismatch between eq. 4 and eq. 2 becomes significant. In the cases studied here, $M>10 N_{d}$ in all cases and this curvature was not observed. If the detection threshold is increased, e.g. use of a higher OD threshold, then curvature is observed. Conversely, lowering the threshold would reduce any observed curvature. Equation 4 does not require the estimation of the maximum population density (MPD) and in the absence of a lag is a two parameter model. Rearranging eq. 4 results in the Malthusian approximation of biological growth - i.e. growth without limit. The value of $\mathrm{M}$ is, however, used in the full form of the logistic model. M can be obtained through plate count, from dilutions of the MPD culture to produce a calibration curve using OD or from using the phenomenon of curvature discussed above.

When a temperature shunt was applied to growing bacteria, the cultures reduced or increased their growth rate commensurate with the incubation temperature. When cultures were shunted 
281 from a lower temperature to a higher temperature there was no evidence of an induced lag and 282 growth continued at the rate dictated by the new temperature. When cultures were shunted from a 283 higher to a lower temperature condensation on the inside of the plate lid occurred and this led to 284 unusable data for a period after the shunt (the period depended on the temperature difference).

285 From the observed, fitted and predicted data it can be concluded that no induction of lag occurred 286 when moving from the higher to the lower temperatures used: the intercept of the regression lines 287 for each temperature coincide at the time of the temperature shunt, if lags were present this would 288 not occur (e.g. Figure 7).

289 290 291 292 293

Page 14 


\section{References}

295 Augustin, J.-C., Rosso, L., and Carlier, V., 1999. Estimation of temperature dependent growth rate 296 and lag time of Listeria monocytogenes by optical density measurements, Journal of

297 Microbiological Methods 38, 137-146.

298

Baranyi, J., Robinson, T.P., Kaloti, A., and Mackey, B.M., 1995. Predicting growth of Brochothrix thermosphacta at changing temperature, International Journal of Food Microbiology 27, 61-75.

Bovill, R., Bew, J., Cook, N., D’Agostino, M., Wilkinson, N., and Baranyi, J., 2000. Predictions of 305 growth for Listeria monocytogenes and Salmonella during fluctuating temperature, International

Cuppers, H.G.A.M and Smelt, J.P.P.M., 1993. Time to turbidity measurement as a tool for modelling spoilage by Lactobacillus. Journal of Industrial Microbiology 12, 168-171. Journal of Food Microbiology 59, 157-165.

Corradini, M.G. and Peleg, M. 2005. Estimating non-isothermal bacterial growth in foods from isothermal experimental data. Journal of Applied Microbiology 99, 187-200.

Dalgaard, P., Buch, P., and Silberg, S.,2002. Seafood Spoilage Predictor-development and distribution of a product specific application software, International Journal of Food Microbiology

Dalgaard, P., Ross T., Kamperman, L., Neumeyer, K., and McMeekin, T.A., 1994. Estimation of bacterial growth rates from turbidimetric and viable count data. International Journal of Food Microbiology 23, 391-404. conditions. Applied and Environmental Microbiology 67,1821-1829. 
327 Koutsoumanis, K., Stamatiou, A., Skandamis, P. and Nychas, G.-J.E., 2006. Development of a 328 microbial model for the combined effect of temperature and $\mathrm{pH}$ on spoilage of ground meat, and 329 validation of the model under dynamic temperature conditions. Applied and Environmental 330 Microbiology 72,124-134.

$332 \mathrm{Li}, \mathrm{K} .-\mathrm{Y}$. and Torres, A. J., 1993. Microbial growth estimation in liquid media exposed to 333 temperature fluctuations. Journal of Food Science 58, 644-648. turbidimetric data for the construction of kinetic models. Journal of Industrial Microbiology 12, 277285.

Mytilinaios, I., Salih, M., Schofield, H.K. and Lambert, R.J.W. 2011. Growth curve prediction from optical density data. International Journal of Food Microbiology submitted.

342 Taoukis, P.S., Koutsoumanis, K., Nychas, G.-J.E., 1999. Use of time temperature integrators and 343 predictive modelling for shelf life control of chilled fish under dynamic storage conditions.

344 International Journal of Food Microbiology 53, 21- 31.

Thomas, C. and O'Beirne, D., 2000. Evaluation of the impact of short-term temperature abuse on the microbiology and shelf life of a model ready-to-use vegetable combination product, International Journal of Food Microbiology 59, 47-57. 
Table 1. Isothermal Rate data

\begin{tabular}{cccccccccc}
\hline Organism & Temp/ $/{ }^{\circ} \mathrm{C}$ & gradient & $\mathrm{LCl}$ & $\mathrm{UCl}$ & Intercept & $\mathrm{LCl}$ & $\mathrm{UCl}$ & $\mathrm{r}^{2}$ & Obs \\
\hline Listeria & 25 & -183.40 & -185.94 & -180.86 & 1687.6 & 1671.7 & 1703.6 & 0.993 & 153 \\
monocytogenes & 30 & -130.30 & -131.90 & -128.70 & 1221.4 & 1211.0 & 1231.7 & 0.994 & 153 \\
& 37 & -109.98 & -110.85 & -109.10 & 999.22 & 993.90 & 1004.6 & 0.997 & 160 \\
\hline Pseudomonas & 25 & -202.24 & -205.33 & -199.15 & 1908.7 & 1889.2 & 1928.1 & 0.991 & 161 \\
aeruginosa & 27 & -140.73 & -143.54 & -137.92 & 1295.1 & 1279.1 & 1311.1 & 0.984 & 157 \\
& 30 & -123.84 & -125.24 & -122.43 & 1122.4 & 1114.3 & 1130.5 & 0.994 & 154 \\
& 34 & -99.17 & -100.80 & -97.54 & 883.05 & 873.74 & 892.34 & 0.989 & 157 \\
& 35 & -96.04 & -97.52 & -94.57 & 889.61 & 880.60 & 898.62 & 0.991 & 149 \\
& 37 & -91.80 & -92.86 & -90.75 & 846.13 & 840.00 & 852.27 & 0.995 & 157 \\
& 39 & -91.38 & -93.26 & -89.49 & 826.70 & 818.78 & 834.78 & 0.987 & 122 \\
& 42 & -100.84 & -102.67 & -99.01 & 923.14 & 911.90 & 934.37 & 0.988 & 147 \\
& 45 & -125.81 & -128.41 & -123.21 & 1137.8 & 1121.7 & 1153.9 & 0.983 & 160 \\
\hline
\end{tabular}

Page 17

CONFIDENTIAL: Cranfield Health: Applied Microbiology

This document may not be reproduced or disclosed to third parties without prior authorisation. 
Table 2. Temperature shifts: Listeria monocytogenes

\begin{tabular}{|c|c|c|c|c|c|c|c|c|c|c|}
\hline & \multicolumn{5}{|c|}{25 to $37^{\circ} \mathrm{C}$} & \multicolumn{5}{|c|}{37 to $25^{\circ} \mathrm{C}$} \\
\hline & & Coefficients & LCL & UCL & $\begin{array}{c}r^{2} \\
\text { (obs) }\end{array}$ & & Coefficients & LCL & UCL & $\begin{array}{c}r^{2} \\
\text { (obs) }\end{array}$ \\
\hline \multirow{2}{*}{$\begin{array}{c}\mathrm{t}<400 \\
\text { mins }\end{array}$} & Intercept & 1758.9 & 1645.7 & 1872.0 & 0.943 & Intercept & 972.97 & 954.82 & 991.12 & 0.984 \\
\hline & $\mathrm{mo}$ & -194.75 & -209.15 & -180.35 & $(47)$ & $\mathrm{mo}$ & -107.88 & -110.46 & -105.30 & (112) \\
\hline \multirow{4}{*}{$\begin{array}{l}t>400 \\
\text { mins }\end{array}$} & Intercept & 1121.9 & 1110.1 & 1133.7 & 0.988 & Intercept & 1441.0 & 1418.5 & 1463.4 & 0.992 \\
\hline & $\mathrm{m} 1$ & -104.25 & -106.47 & -102.02 & (103) & $\mathrm{m} 1$ & -198.8 & -204.40 & -193.21 & (45) \\
\hline & \multicolumn{5}{|c|}{30 to $37^{\circ} \mathrm{C}$} & \multicolumn{5}{|c|}{37 to $30^{\circ} \mathrm{C}$} \\
\hline & & Coefficients & LCL & UCL & $\begin{array}{c}r^{2} \\
\text { (obs) }\end{array}$ & & Coefficients & LCL & UCL & $\begin{array}{c}r^{2} \\
\text { (obs) }\end{array}$ \\
\hline \multirow{2}{*}{$\begin{array}{c}\mathrm{t}<410 \\
\text { mins }\end{array}$} & Intercept & 1333.6 & 1302.5 & 1364.6 & 0.985 & Intercept & 983.14 & 975.06 & 991.23 & 0.997 \\
\hline & $\mathrm{mo}$ & -147.31 & -151.55 & -143.07 & $(72)$ & $\mathrm{mo}$ & -109.30 & -110.48 & -108.12 & $(108)$ \\
\hline \multirow{2}{*}{$\begin{array}{c}t>410 \\
\text { mins }\end{array}$} & Intercept & 1068.5 & 1057.7 & 1079.4 & 0.991 & Intercept & 1166.1 & 1144.5 & 1187.7 & 0.986 \\
\hline & $\mathrm{m} 1$ & -106.60 & -108.82 & -104.38 & (84) & $\mathrm{m} 1$ & -145.56 & -151.02 & -140.10 & $(44)$ \\
\hline
\end{tabular}

Page 18

CONFIDENTIAL: Cranfield Health: Applied Microbiology

This document may not be reproduced or disclosed to third parties without prior authorisation. 
Table 3. Temperature shifts: Pseudomonas aeruginosa

\begin{tabular}{|c|c|c|c|c|c|c|c|c|c|c|}
\hline & \multicolumn{4}{|c|}{25 to $39^{\circ} \mathrm{C}$} & \multicolumn{6}{|c|}{39 to $25^{\circ} \mathrm{C}$} \\
\hline & & Coefficients & LCL & UCL & $\begin{array}{c}\mathrm{r}^{2} \\
\text { (obs) }\end{array}$ & & Coefficients & LCL & UCL & $\begin{array}{c}r^{2} \\
\text { (obs) }\end{array}$ \\
\hline \multirow{2}{*}{$\begin{array}{l}\mathrm{t}<300 \\
\text { mins }\end{array}$} & Intercept & 2081.9 & 1783.8 & 2380.0 & 0.91 & Intercept & 854.35 & 820.60 & 888.1 & 0.951 \\
\hline & $\mathrm{mo}$ & -228.26 & -264.20 & -192.33 & $(19)$ & $\mathrm{mo}$ & -91.89 & -96.58 & -87.21 & $(80)$ \\
\hline \multirow{2}{*}{$\begin{array}{l}t>300 \\
\text { mins }\end{array}$} & Intercept & 1035.8 & 1025.4 & 1046.1 & 0.987 & Intercept & 1639.5 & 1600.7 & 1678.2 & 0.972 \\
\hline & $\mathrm{m} 1$ & -91.79 & -93.57 & -90.00 & $(140)$ & $\mathrm{m} 1$ & -208.55 & -216.8 & -200.31 & (75) \\
\hline
\end{tabular}

\begin{tabular}{lcccccccccc}
\hline & \multicolumn{3}{c}{34 to $39^{\circ} \mathrm{C}$} & \multicolumn{3}{c}{39 to $34^{\circ} \mathrm{C}$} \\
& & Coefficients & $\mathrm{LCL}$ & $\mathrm{UCL}$ & $\begin{array}{c}\mathrm{r}^{2} \\
(\mathrm{obs})\end{array}$ & & Coefficients & $\mathrm{LCL}$ & $\mathrm{UCL}$ & $\begin{array}{c}\mathrm{r}^{2} \\
(\mathrm{obs})\end{array}$ \\
\hline $\mathbf{t}<\mathbf{3 0 0}$ & Intercept & 907.07 & 866.26 & 947.89 & 0.954 & Intercept & 811.66 & 832.49 & 854.58 & 0.980 \\
$\mathbf{m i n s}$ & $\mathrm{m} 0$ & -99.12 & -104.81 & -93.43 & $(61)$ & $\mathrm{m} 0$ & -89.00 & -91.96 & -86.03 & $(75)$ \\
\hline $\mathbf{t}>\mathbf{3 0 0}$ & Intercept & 868.04 & 855.48 & 880.59 & 0.982 & Intercept & 872.48 & 854.58 & 890.38 & 0.973 \\
mins & $\mathrm{m} 1$ & -92.64 & -95.24 & -90.02 & $(93)$ & $\mathrm{m} 1$ & -100.47 & -104.55 & -93.39 & $(69)$ \\
\hline \hline
\end{tabular}

Page 19

CONFIDENTIAL: Cranfield Health: Applied Microbiology

This document may not be reproduced or disclosed to third parties without prior authorisation. 
Table 4. Observed parameters for the $37 / 25 / 37 / 25$ and 25/37/25/37 temperature shunts of Listeria monocytogenes

\begin{tabular}{|c|c|c|c|c|c|c|}
\hline time & Temp & Parameter & Estimate & $\mathrm{LCl}$ & $\mathrm{UCl}$ & r2 (obs) \\
\hline & & $\log I d$ & 9.48 & 9.26 & 9.71 & \\
\hline$<360$ & 37 & $\mathrm{mo}$ & -107.92 & -108.36 & -106.47 & $0.998(38)$ \\
\hline$<600$ & 25 & $\mathrm{~m} 1$ & -179.29 & -188.04 & -170.54 & $0.992(17)$ \\
\hline$<900$ & 37 & $\mathrm{~m} 2$ & -104.62 & -106 & -103.25 & $0.998(52)$ \\
\hline$>900$ & 25 & $\mathrm{~m} 3$ & - & - & - & no obs \\
\hline \multirow[t]{2}{*}{ time } & Temp & Parameter & Estimate & $\mathrm{LCl}$ & $\mathrm{UCl}$ & r2 (obs) \\
\hline & & $\log I d$ & 9.58 & 7.98 & 11.52 & \\
\hline$<360$ & 25 & $\mathrm{mo}$ & -193.5 & -212.59 & -174.4 & $0.981(12)$ \\
\hline$<600$ & 37 & $\mathrm{~m} 1$ & -104.73 & -106.54 & -102.93 & $0.997(42)$ \\
\hline$<900$ & 25 & $\mathrm{~m} 2$ & -174.69 & -189.12 & -160.26 & $0.971(21)$ \\
\hline$>900$ & 37 & $\mathrm{~m} 3$ & -109.52 & -114.69 & -104.35 & 0.984 \\
\hline
\end{tabular}

Page 20

CONFIDENTIAL: Cranfield Health: Applied Microbiology

This document may not be reproduced or disclosed to third parties without prior authorisation. 


\section{Caption to Figures}

Figure 1.The geometrical basis for equation 5 : for a given rate (M0), over the time period $\mathrm{T}_{\mathrm{x}}$ initial inocula between $\log I_{D}-\log I_{x}$ will reach the detection threshold of $\log I_{d}$. At $T_{x}$ the rate is changed (M1) and the TTD now follow the new rate. If a lag is induced a vertical separation at $T_{x}$ equal to the time of lag will be present before growth recommences.

Figure 2. Optical density/incubation time curves for Listeria monocytogenes incubated at $25^{\circ} \mathrm{C}$.

Figure 3a. Observed TTD data for multiple initial inocula of L.monocytogenes (L252) at 25 (triangles), 30 (squares) and $37^{\circ} \mathrm{C}$ (circles). The solid lines are the fitted regression lines (Table 1) Figure 3b. Observed TTD data for multiple initial inocula of $P$.aeruginosa ATCC 15442) at 30 (squares) and $37^{\circ} \mathrm{C}$ (circles). The solid lines are the fitted regression lines (Table 1)

Figure 4. Observed TTD data for L.monocytogenes incubating at 37 or $25^{\circ} \mathrm{C}$ with a temperature shunt to $25^{\circ} \mathrm{C}$ or $37^{\circ} \mathrm{C}$ (open circles and open squares respectively) after 400 minutes incubation at the initial temperature. Solid lines are the fitted regression lines (Table 2).

Figure 5. Observed TTD data for L.monocytogenes incubating at 37 or $30^{\circ} \mathrm{C}$ with a temperature shunt to $30^{\circ} \mathrm{C}$ or $37^{\circ} \mathrm{C}$ (open circles and open squares respectively) after 410 minutes incubation at the initial temperature. Solid lines are the fitted regression lines (Table 2).

Figure 6. Observed TTD data (symbols)for an initial plate of multiple inocula of $P$.aeruginosa incubating at $37^{\circ} \mathrm{C}$ for 300 minutes, replaced by an identical filled plate after incubation at $30^{\circ} \mathrm{C}$ for 300 minutes. The solid lines are the predicted TTD based on the data of Table 1 and the use of the logistic model to calculate the expected increase in numbers in both plates.

Figure 7. Observed TTD data for L.monocytogenes incubating at $37-25-37-25^{\circ} \mathrm{C}$ (open circles) or $25-37-25-37^{\circ} \mathrm{C}$ (open squares) with temperature shunts occurring at 360,600 and 900 minutes. The solid lines are the predicted values based on the data of Table 1, with $\mathrm{Nd}=9.4$.

Figure 8. Observed TTD data (symbols) and predicted data (solid line) from a single Bioscreen incubating at $37^{\circ} \mathrm{C}$ for multiple inocula of $L$. monocytogenes undergoing plate changes to and from another machine incubating at $25^{\circ} \mathrm{C}$ (see figure 7). The solid lines are the predicted TTD based on the data of Table 1 and the use of the logistic model to calculate the expected increase in numbers in both plates during the periods of incubations at 37 and $30^{\circ} \mathrm{C}$.

Page 21

CONFIDENTIAL: Cranfield Health: Applied Microbiology

This document may not be reproduced or disclosed to third parties without prior authorisation. 


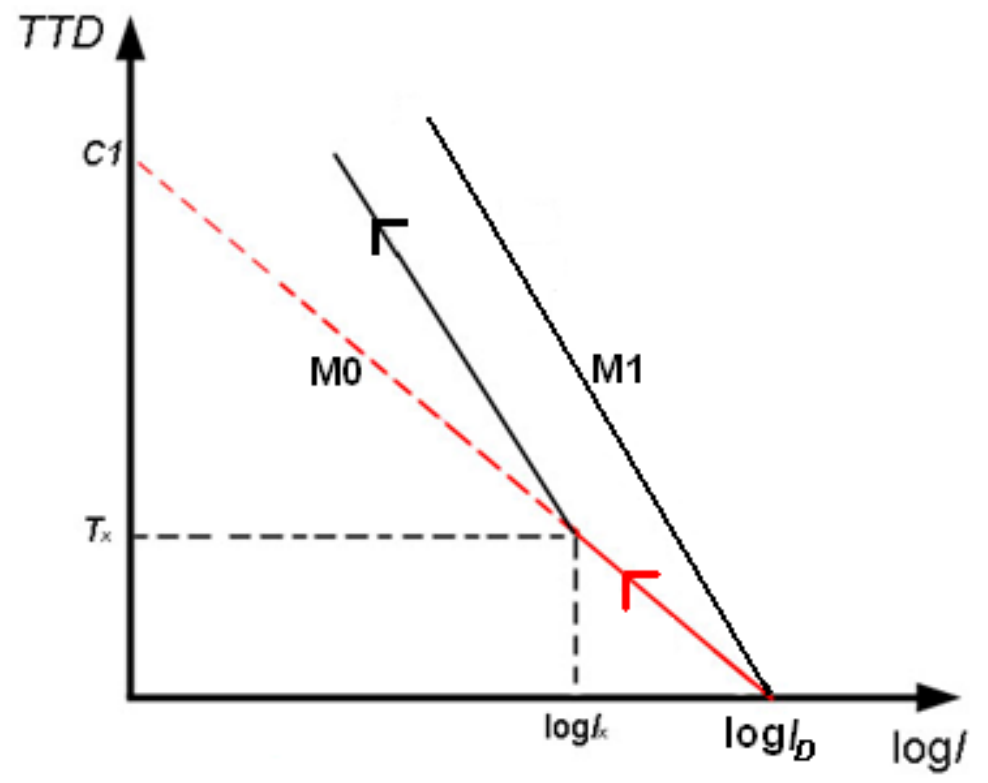

Figure 1.

Page 22 


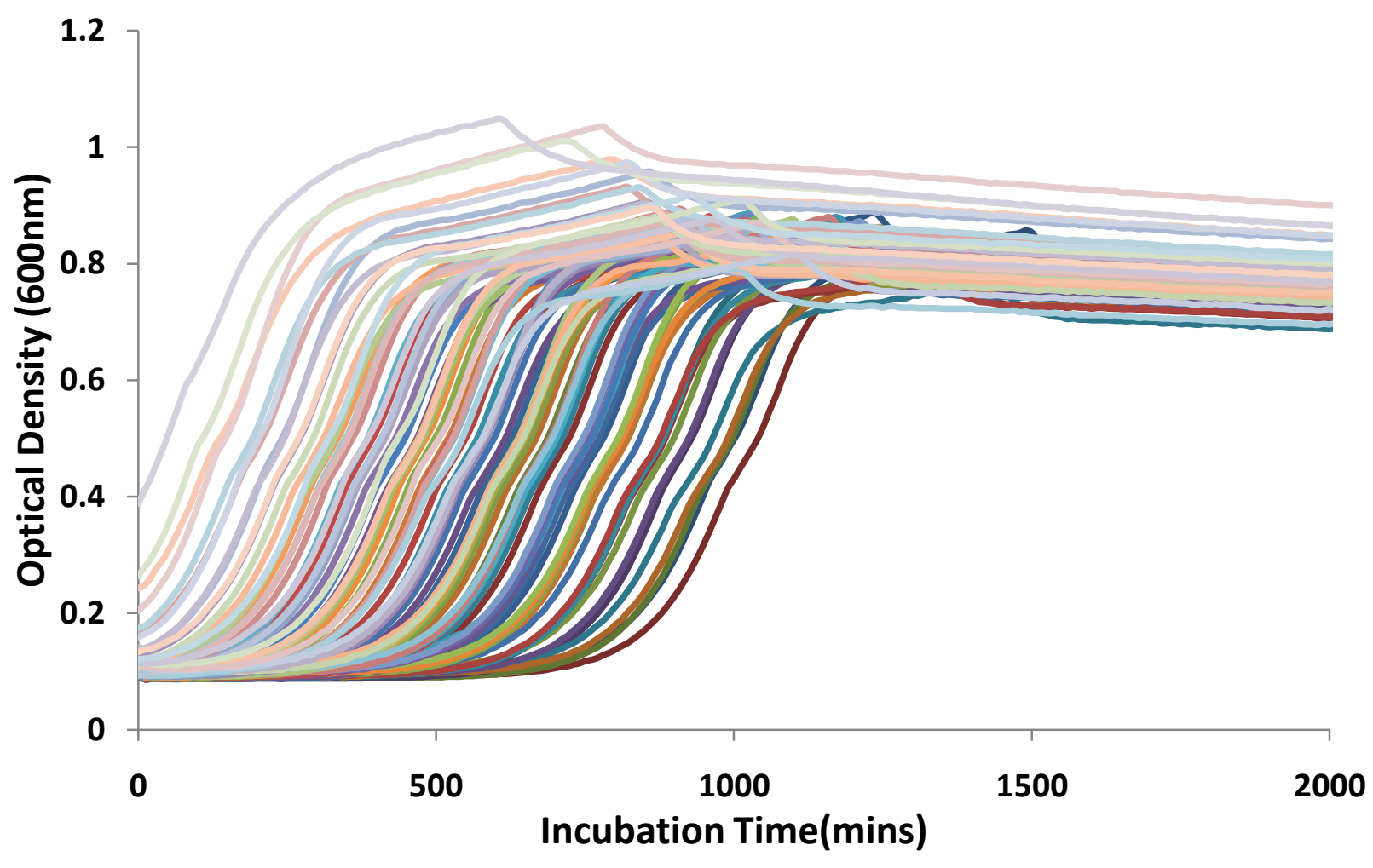

Figure 2.

Page 23

CONFIDENTIAL: Cranfield Health: Applied Microbiology

This document may not be reproduced or disclosed to third parties without prior authorisation. 
Figure $3 a$

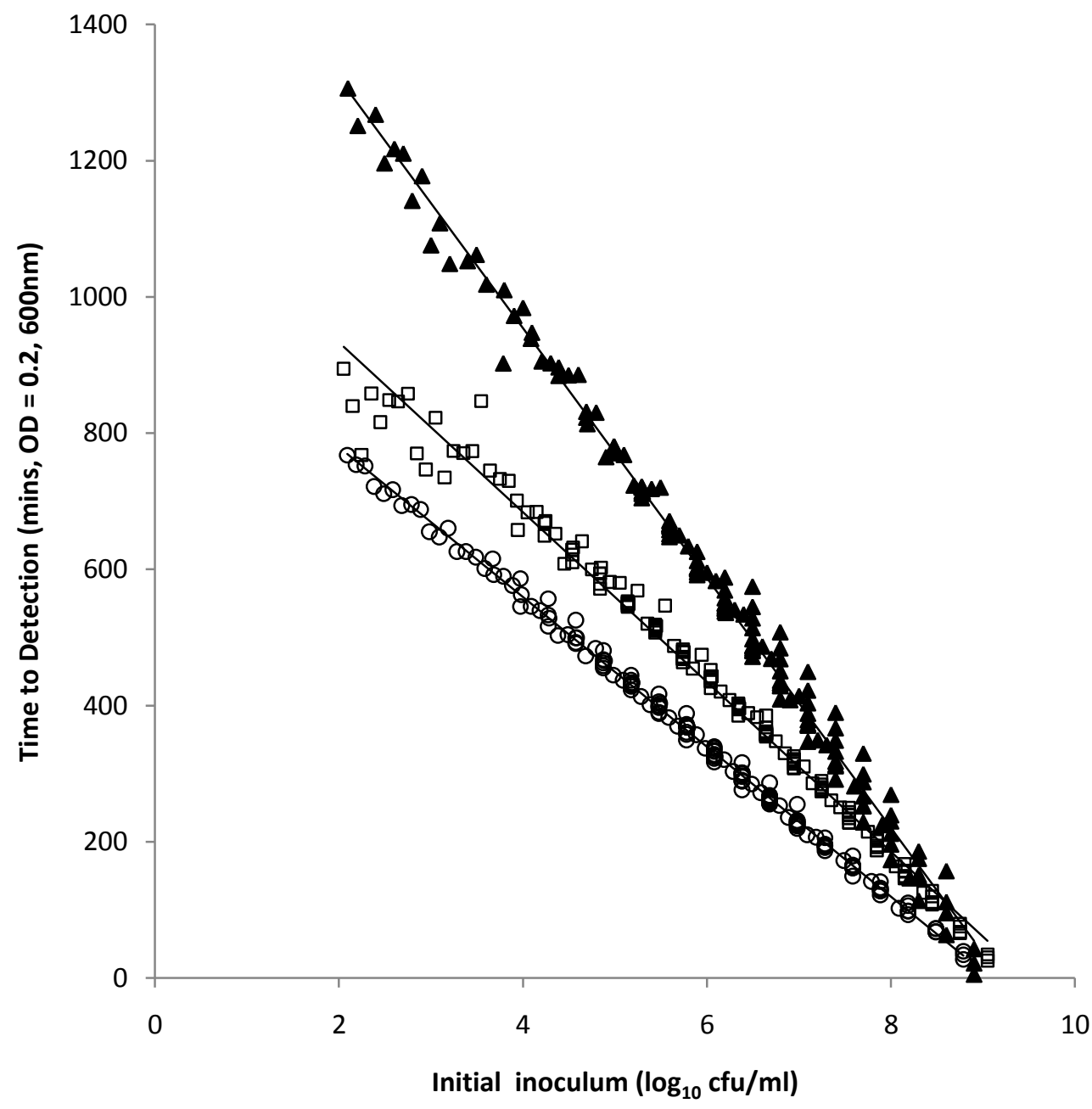

Page 24

CONFIDENTIAL: Cranfield Health: Applied Microbiology

This document may not be reproduced or disclosed to third parties without prior authorisation. 


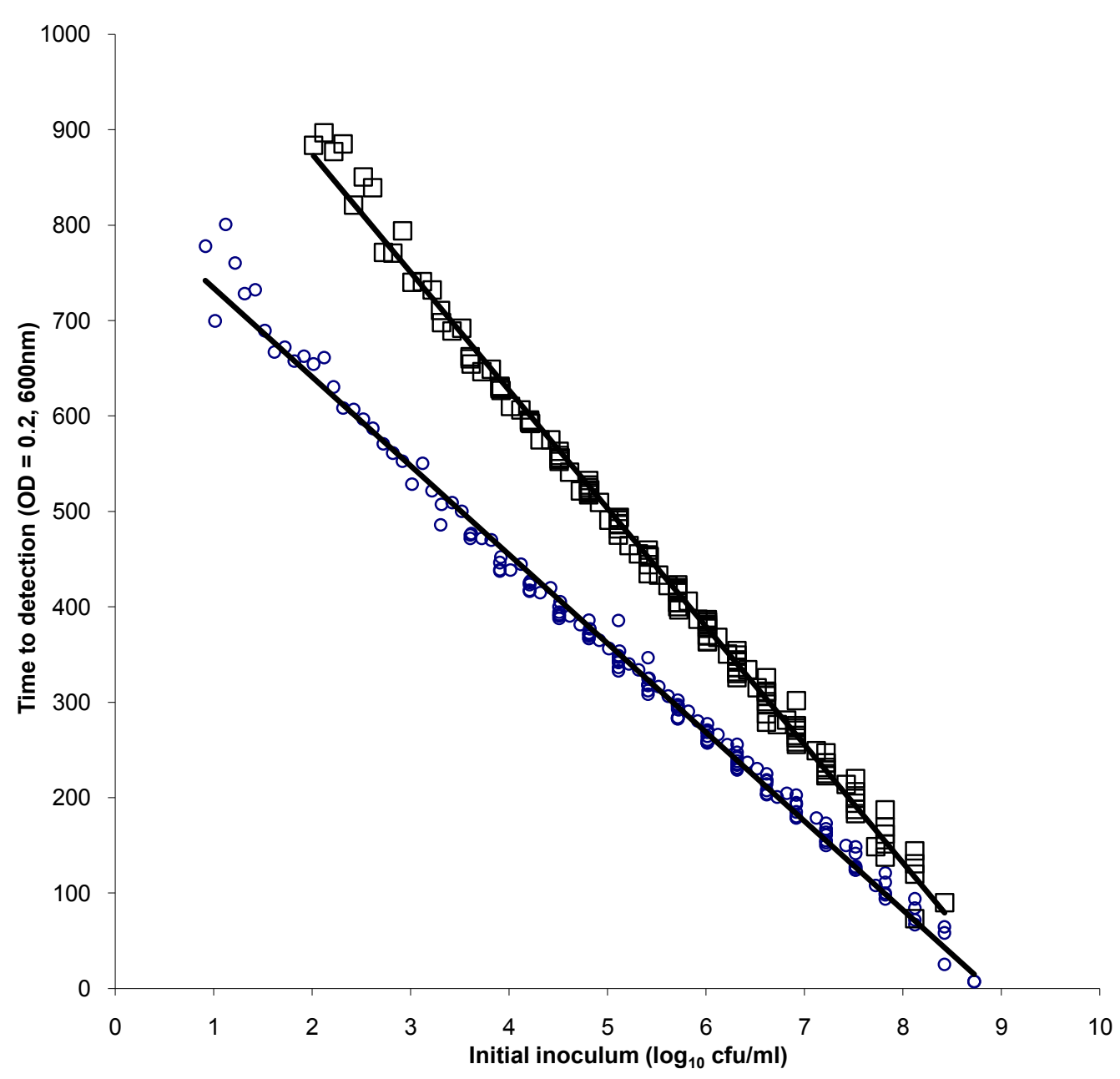

Figure 3b.

Page 25 
Figure 4.

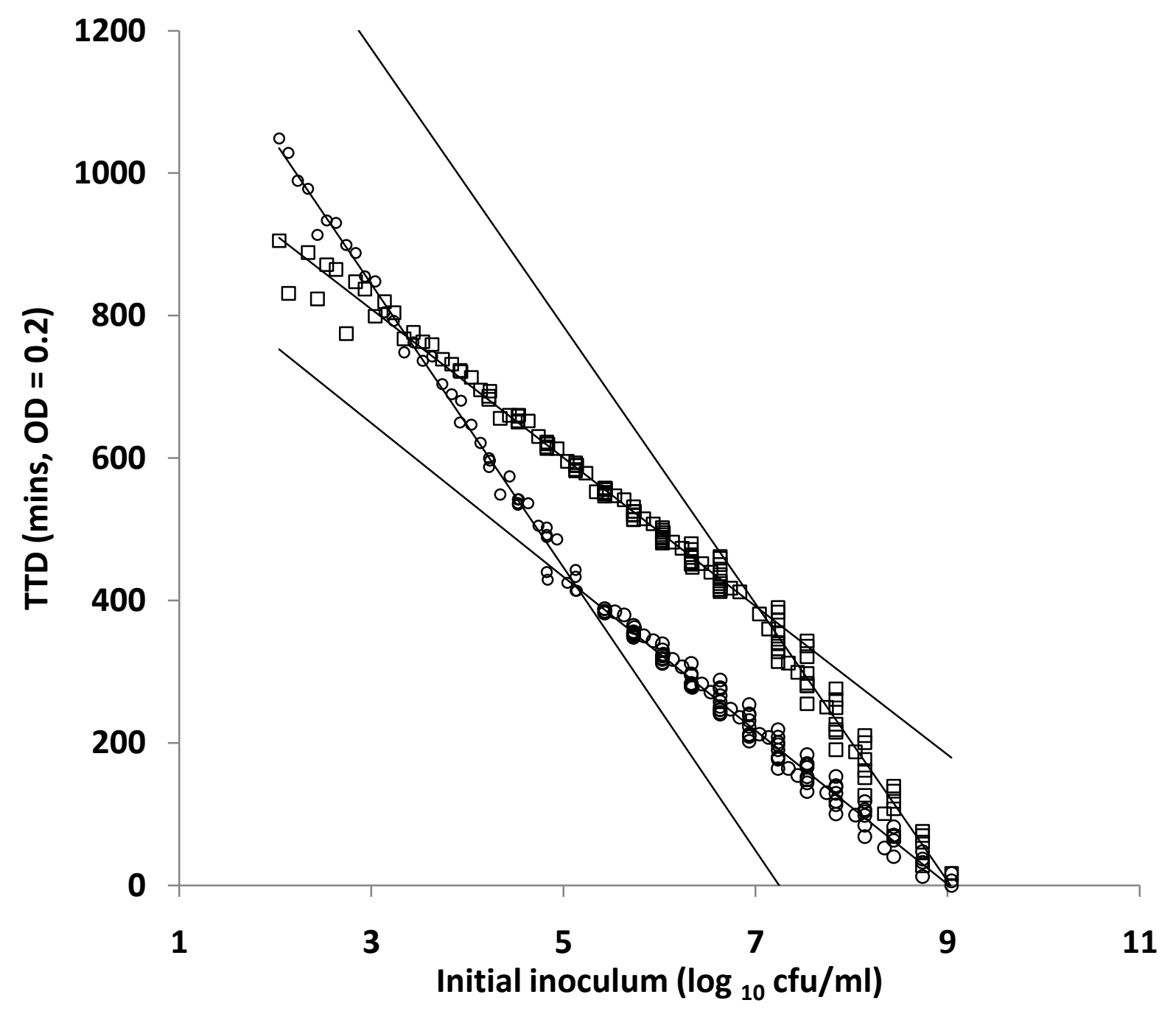

Page 26 
Figure 5.

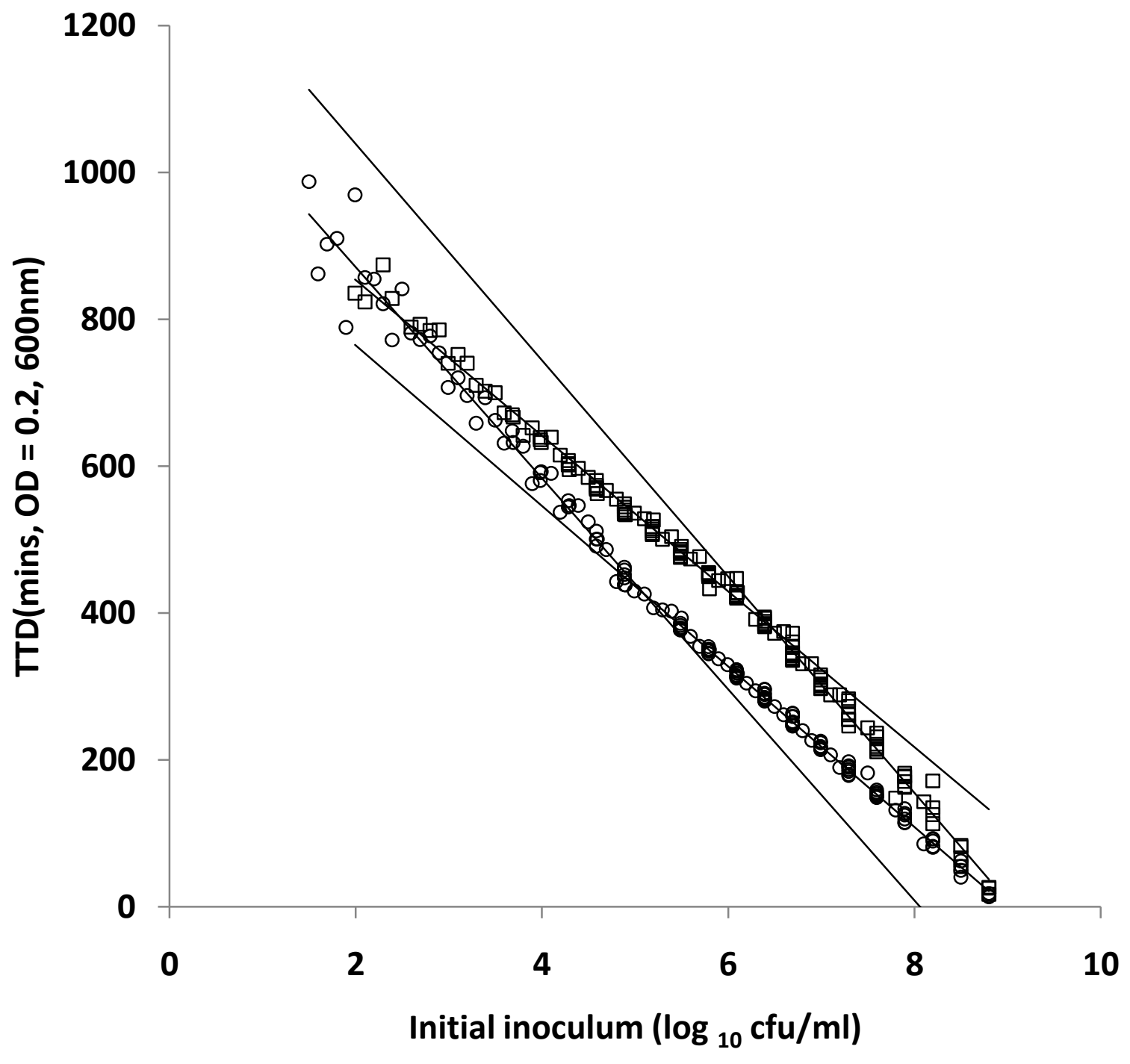

Page 27 
Figure 6

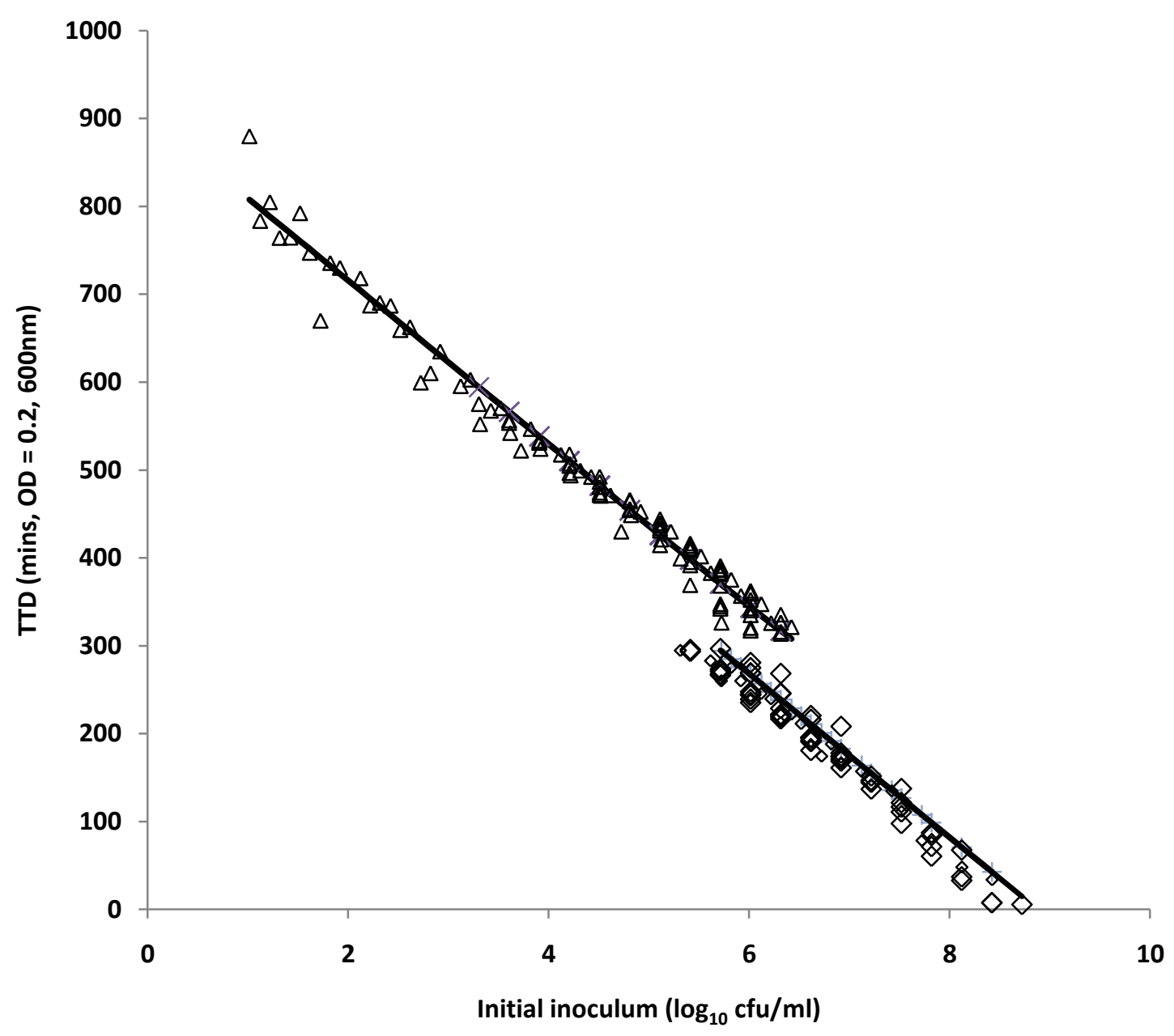

Page 28

CONFIDENTIAL: Cranfield Health: Applied Microbiology

This document may not be reproduced or disclosed to third parties without prior authorisation. 
Figure 7

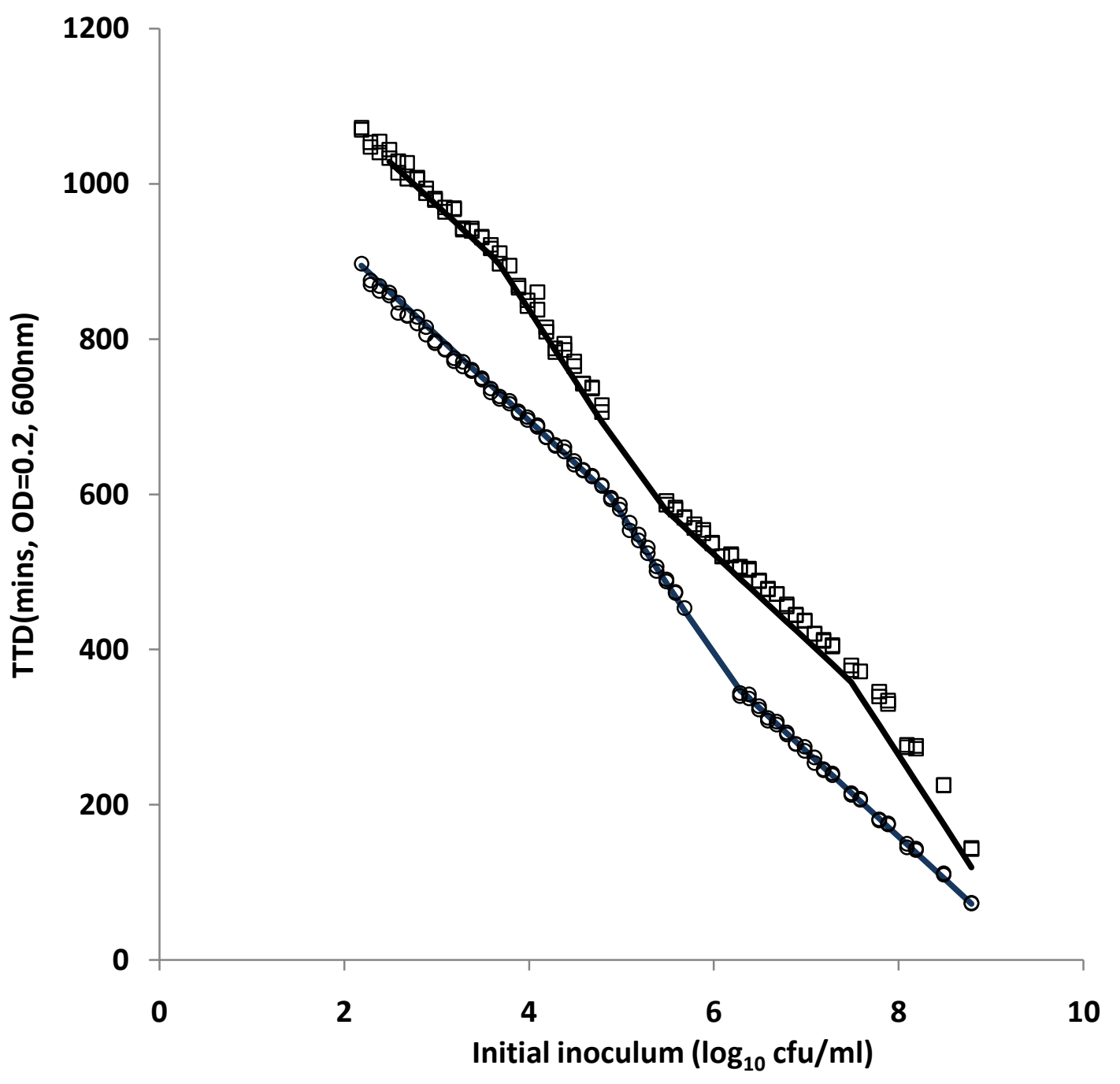

Page 29 
Figure 8

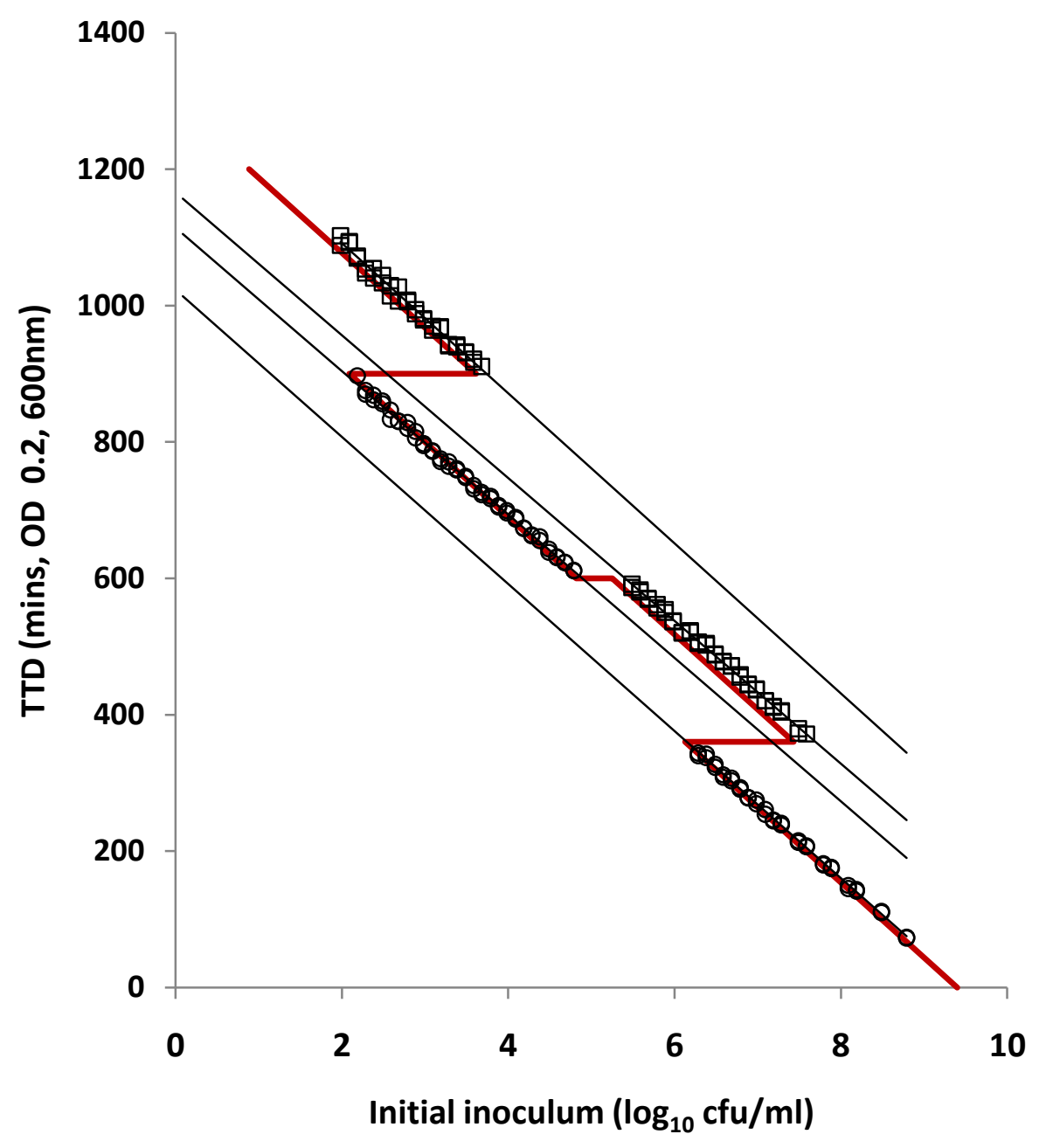

Page 30 